\title{
SEA - A Simplified Employee Assessment
}

\author{
L. E. Busby
}

April 23, 2001

U.S. Department of Energy

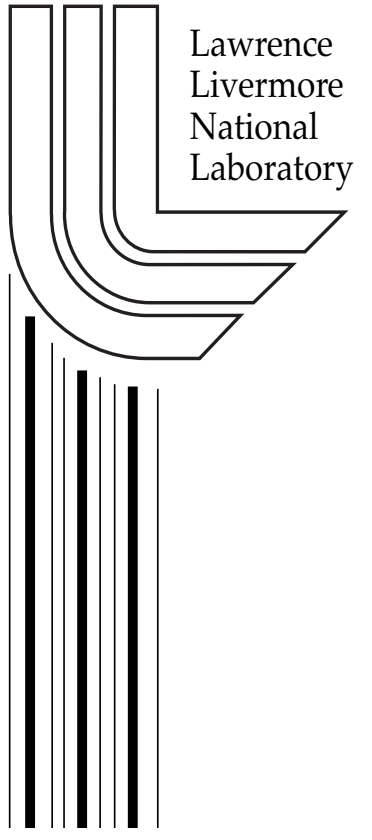




\section{DISCLAIMER}

This document was prepared as an account of work sponsored by an agency of the United States Government. Neither the United States Government nor the University of California nor any of their employees, makes any warranty, express or implied, or assumes any legal liability or responsibility for the accuracy, completeness, or usefulness of any information, apparatus, product, or process disclosed, or represents that its use would not infringe privately owned rights. Reference herein to any specific commercial product, process, or service by trade name, trademark, manufacturer, or otherwise, does not necessarily constitute or imply its endorsement, recommendation, or favoring by the United States Government or the University of California. The views and opinions of authors expressed herein do not necessarily state or reflect those of the United States Government or the University of California, and shall not be used for advertising or product endorsement purposes.

This work was performed under the auspices of the U. S. Department of Energy by the University of California, Lawrence Livermore National Laboratory under Contract No. W-7405-Eng-48.

This report has been reproduced directly from the best available copy.

Available electronically at http://www.doc.gov/bridge

Available for a processing fee to U.S. Department of Energy

And its contractors in paper from

U.S. Department of Energy

Office of Scientific and Technical Information

P.O. Box 62

Oak Ridge, TN 37831-0062

Telephone: (865) 576-8401

Facsimile: (865) 576-5728

E-mail: reports@adonis.osti.gov

Available for the sale to the public from

U.S. Department of Commerce

National Technical Information Service

5285 Port Royal Road

Springfield, VA 22161

Telephone: (800) 553-6847

Facsimile: (703) 605-6900

E-mail: orders@ntis.fedworld.gov

Online ordering: http://www.ntis.gov/ordering.htm

OR

Lawrence Livermore National Laboratory

Technical Information Department's Digital Library

http:/ / www.llnl.gov/tid/Library.html 
UCRL-ID-143566

\section{SEA - A simplified employee assessment}

Lee E. Busby

Group leader, SCA division

LLNL

ABSTRACT

This paper presents a proposal for modifying the current employee annual evaluation process in SCAD. It purports to simplify that process, primarily by breaking up the resultant document into a set of more or less independent components. It claims to reduce the overall time and effort required from each actor.

The views represented are those of the authors and do not represent those of Lawrence Livermore National Laboratory, the University of California, the United States Government, or any other institution.

April 23, 2001

Approved for public release; further dissemination unlimited 
This document was prepared as an account of work sponsored by an agency of the United States Government. Neither the United States Government nor the University of California nor any of their employees, makes any warranty, express or implied, or assumes any legal liability or responsibility for the accuracy, completeness, or usefulness of any information, apparatus, product, or process disclosed, or represents that its use would not infringe privately owned rights. Reference herein to any specific commercial product, process, or service by trade name, trademark, manufacturer, or otherwise, does not necessarily constitute or imply its endorsement, recommendation, or favoring by the United States Government or the University of California. The views and opinions of authors expressed herein do not necessarily state or reflect those of the United States Government or the University of California, and shall not be used for advertising or product endorsement purposes.

This work was performed under the auspices of the U. S. Department of Energy by the University of California, Lawrence Livermore National Laboratory under Contract No. W-7405-Eng-48.

This report has been reproduced directly from the best available copy.

Available to DOE and DOE contractors from the

Office of Scientific and Technical Information

P.O. Box 62, Oak Ridge, TN 37831

Prices available from (423) 576-8401

http://apollo.osti.gov/bridge/

Available to the public from the

National Technical Information Service

U.S. Department of Commerce 5285 Port Royal Rd., Springfield, VA 22161 http://www.ntis.gov/

\section{OR}

Lawrence Livermore National Laboratory Technical Information Department's Digital Library http://www.llnl.gov/tid/Library.html 
This paper presents a proposal for modifying the current employee annual evaluation process in SCAD. It purports to simplify that process, primarily by breaking up the resultant document into a set of more or less independent components. It claims to reduce the overall time and effort required from each actor.

\section{Forward to version 2}

The first version of my proposal has benefitted substantially from comments by many group leaders and the division leader of SCA Division. I am especially grateful to Dennis Braddy and Joyce Moulden for their review and encouragement. Joyce made significant contributions and improvements to the $P R F$.

There were several changes made in response to the initial review: First, a more complete discussion of the design goals for the PRF is included, in addition to changes made to the PRF. Second, a section contrasting the "rights, responsibilities, and ownership" in our current appraisal process with those in the SEA has been added. It attempts to define and clarify an area that produced some of the most heated opinions during the first review.

Third, a form for reviewing this SEA proposal itself has been appended, in hopes that my gentle readers will set me straight regarding where I have gone wrong, or not. Finally, use of the "editorial $w e$ " has been elided from the document. It just seemed simpler that way.

\section{Introduction}

This paper does not much address the substantive content or even purpose of our current employee review system. It focuses more simply on the form and process. The proposal may be close enough in substance that it could be reasonable to mix new and old style evaluations, depending on the preferences of individual employees and supervisors. Allowing our employees to "vote with their feet" would be the acid test of any proposal aiming to improve the evaluation process.

The proposal also excludes consideration or much discussion of the SCAD and CAO ranking or salary allocation processes. Some discussion of how the proposal might work in a network-based (Web) environment is included, but that is largely left to the future.

Although the proposal may be a "baby step" in terms of laying out change to the current CAO rewards system, it does attempt to illuminate some of the failings of our current process and policy, and it attempts to show that there may be simple and reasonable changes that could improve it. I hope that it will stimulate other readers to carry out in-depth proposals of their own - there is a large reservoir of talent and experience entirely within CAO that can "just do it."

\section{Description of the SEA}

\section{A. The Personnel Review Form}

The heart of the SEA is the Personnel Review Form (PRF). (A sample PRF is attached.) The $\mathrm{PRF}$ is envisioned as a pre-printed, standardized form that all actors utilize to record their assessments of a given person. It allows both prose commentary and multiple-choice style responses to be entered. The sample PRF is based on the seven job performance factors currently used throughout CAO.

The questions on the PRF are of two sorts: The majority of the questions attempt to characterize some aspect of performance, usually by marking 
a point on a scale between contrasting ways of talking about that factor. There is generally not any single right or best answer for these questions. The second type of question asks the reviewer to make an overall assessment of performance in an area. The scale adopted for the assessment questions is the same as in current use by the Engineering directorate at LLNL.

For a given employee's review, the persons who will complete a PRF are the same as the group that currently contributes input to their evaluation:

1. Self;

2. Supervisor(s), programmatic and matrix as appropriate;

3. Direct reports;

4. Peers;

5. Customers.

The first three categories are required - the list is compiled by the employee's supervisor. The last two categories are optional, based on the desires of this employee. Names in all categories would be forwarded to a division- or departmental-level administrator, who mails a PRF to all candidate reviewers. Completed PRF's are returned to the same administrator, who distributes them back to the appropriate supervisor.

\section{B. Employee contribution to the SEA}

The second major component of the SEA is the employee's contribution. This consists of two parts, the second optional. Part 1 is simply the employee's self-assessment, using the PRF as described above. Self-assessments are likely to include additional prose commentary, and space is provided on the standard PRF.

If the employee chooses, they may also contribute an Annual Progress Report (APR) to their performance review. This would contain similar information to that in the sections titled Description of assigned duties and responsibilities, and Tasks and Accomplishments, taken from our current evaluation format. However, an APR has several distinguishing characteristics:

1. It is written in first person, not third;

2. It is a complete standalone document on its own;

3. Within broad guidelines, the employee is free to include whatever material they choose;

4. The supervisor does not edit or modify the
APR;

5. The APR is submitted as hard copy, up to (say) 5 letter-size pages. There are no other restrictions on format, tools, software compatibility, etc.

If an APR is to be submitted, it is due by July 1 (say) in the evaluation year.

\section{Supervisor Summary}

The third major component of the SEA is the supervisor's summary. This is roughly analogous to the Appraisal and Summary section of our current evaluation. Note that the supervisor has already completed a PRF for the employee, and thus has separately addressed the seven traditional job performance factors. Hence the Summary should collect together all reviewer comments and synthesize an overall statement about this individual's performance. It should normally fit on one or two letter-size pages, although the format may vary as needed. Space for final employee comments on his or her review is required, and the Summary will include that space. The Summary will also include space for required signatures.

\section{Other components}

Our current evaluation includes a couple of other components not yet addressed in the SEA. One is the several kinds of "boilerplate" that describe employee activities and attention to ES\&H matters, affirmative action, etc. Another is the educational and experience data that is currently presented in the title of our evaluation. A draft Certification Form is attached, that attempts to gather together this information into one place. The SEA would include a filled-out and signed copy of this form.

Another component is the IDP (Individual Development Plan.) This is already a separate document in our current evaluation process. So long as it is available in pre-printed form, it is easy to include (or not) with the SEA.

\section{Principles of the SEA}

\section{A. Basic ideas}

The SEA arose in response to an idea session (attended mostly by SCAD group leaders) that named three desires:

1. Make evaluations simpler;

2. Give us a "checklist";

3. Separate out the boilerplate.

In pursuit of the first, the SEA incorporates 
employee and customer input unchanged into the finished review. This is considerably easier if everyone uses the same form for input, and a sample of such a form is included in the proposal. Likewise, the third request is easy enough to standardize, and a form is provided here.

There are some other principles in the SEA that reflect my personal desire to make our evaluation process more "employee-centered."

1. The employee should be given the greatest amount of control otherwise consistent with institutional requirements over the degree of effort they expend on their own review.

2. Employee contributions to their review should be complete in and of themselves not a draft. Words contributed by the employee should be clearly demarcated as their own.

3. Within broad guidelines, the employee should be able to choose tools and formats that they enjoy and are expert in using to prepare and present their input.

4. Comments from reviewers should be included verbatim in the finished document.

\section{B. Design of the PRF}

There were a couple of goals that drove the form of the PRF provided here. One was based on avoiding the many failures of similar forms anecdotally reported by others. These were summarized by P. Miller as the "firewall 9's" outcome, in which individual scores tend asymptotically to the maximum possible, and the process as a whole becomes useless as a jobforce measure. The other goal was similar, but based on a personal conviction that so-called quantitative assessments have little or no legitimate role in our current ranking process. Qualitative assessments are something else, and the PRF therefore attempts to stimulate all reviewers into thinking about people in a variety of ways, some of them hopefully novel. Many questions in the current PRF may be traced to my own experience over the past six years in ranking sessions and other forums where we attempt to compare CAO employees. Much of that struggle can be seen as attempting to understand the context in which our employees work, and the questions in the PRF reflect that bias.

Although the PRF is predominantly composed of characterization and context-setting questions, it does also include questions that ask for a direct assessment. These may or may not be useful to a supervisor; my doubts are in evidence already. However, these questions do have a purpose: They (and their answers) serve as a direct conduit between reviewers and reviewees. This kind of feedback is effective and simple; our review process should support it.

\section{C. "Ownership" and related policies}

There are a couple of mis-conceptions about our current employee review process that contribute to needless misunderstanding and distrust. Many persons act as though they believe the following:

1. Employees are required to provide evaluation input; and

2. Supervisors have the right to change it.

Strictly speaking, neither is true. Current policy is that "employees should supply input ..." (emphasis added). However, there is no specific institutional penalty for failing to do so. (Let me hasten to add that it is definitely not recommended as a way to get ahead, of course.) On the other hand, supplying input is also not optional in any sense. There is a grey area between not optional and not required that is covered by use of the words "should supply input". This grey area sometimes causes misunderstanding between parties who may be using slightly different definitions of the word "required."

Regarding the second statement, what supervisors have is the obligation, authority and access to edit words from several sources into the final document. Those editing decisions, to the extent they may affect employee benefits or compensation, are subject to our standard grievance procedures. (If a supervisor twists the words of someone else in an evaluation, that person may file a grievance, and is likely to win.) Thus the supervisor's privilege does not ascend to the level of a right. If a supervisor receives input that he or she disagrees with, recording this disagreement explicitly, and providing a rationale, is close to what we mean (in my opinion) when we say that a supervisor should own an appraisal.

Simply put, LLNL promises an annual evaluation for its employees as a matter of policy, and it generally delegates the responsibility for producing them to first-line supervisors. If an employee supplies input that is illiterate, ungrammatical, insufficient, or entirely nonexistent, the supervisor is still responsible for providing an evaluation. This is a fine thing, actually, and the SEA does not propose to change 
this aspect of policy.

The SEA does differ with current policy in one important respect. At the moment, an employee's right to incorporate written input into their own evaluation is limited to making comments about the finished document. The SEA proposes that the two components contributed by the employee (PRF and APR) be incorporated verbatim into the evaluation, along with the other reviewers' PRF forms. If this is to be workable in the long term, it must become a matter of institutional policy. That is, while a supervisor may disagree with and refute input received from others in their own Summary, they must nevertheless show us the words. There are some good reasons to consider this change:

1. Any business process should be designed to provide the greatest benefit to the largest number. The great majority of employees in CAO enjoy amiable relations with their supervisor. They understand perfectly that providing excellent evaluation input is an opportunity. The current policy does lead to needless misunderstanding, as discussed in the first paragraphs of this section. Current policy is a vaguely worded and (often) even more vaguely expressed stick, even though actual practice in the vast majority of cases is that employees prepare good input, and supervisors faithfully copy it into evaluations. Policy could be a carrot to address and support that case, as the SEA proposal does. Other benefits to the employee of preparing finished input are discussed elsewhere in this paper.

2. In the small number of cases where there is significant disagreement between a supervisor and an employee or other reviewer, the business process should not discard information. The degree of agreement and correlation between reviewers about an employee's performance is highly significant information to current and future readers of the performance review. The best (and simplest) way to preserve this information is to incorporate verbatim input.

In the spirit of full disclosure, it should be noted that the SEA does not entirely eliminate the grey area referred to above in the discussion of an employee's obligation to provide evaluation input. The second component of SEA employee input the APR - is proposed to be optional, provided at the discretion of the employee. Furthermore, if an employee chooses to provide it, the SEA proposes to include it unchanged in the evaluation package, conceivably over the objections of the supervisor. This policy is clear and easy to understand, and would arguably result in a better outcome in essentially all cases, in my opinion.

However, the first component of SEA employee input - the PRF - is not proposed to be optional. It would therefore fall in the grey area as a "semirequired" piece of input. This fall from grace may be softened because the PRF is designed to be short and simple to complete, and the employee does receive assurance that their selfevaluation will be included whole.

\section{Summary of components and features}

The SEA is composed of several parts:

1. Employee self-evaluation, using the PRF;

2. (Optional) Annual progress report, by employee;

3. Reviewer assessments, using the PRF;

4. Certifications and boilerplate form;

5. Supervisor summary, with employee rejoinders and signatures;

6. IDP (no change from current practice required.)

Relative to our current evaluation process, the employee is given much more control over the extent and form of his or her input to the SEA. The form of the APR encourages initiative from our employees, by allowing them to invest in detailed control over the contents and format, knowing that their words will be preserved for future readers. It encourages cultivation and exercise of careful writing skills. Skill in written communication is still an important predictor of career success, and our review process should give people full opportunity to shine. If a supervisor and employee so choose, it is perfectly alright to produce an APR by iterating the document between them until each is satisfied.

The draft PRF is designed to be nonconfrontational. It utilizes the same criteria as our current CAO process. In the questions that do attempt to probe performance directly, it uses criteria that have been well-tested by our own Engineering directorate. All reviewers are free to skip any questions they please, and contribute prose if that is their preference.

Except for the supervisor's summary, there are no draft documents in the SEA. Every other component is physically included in its original 
form. This greatly simplifies preparation, and ensures the greatest degree of integrity in preserving and transmitting the intentions of all parties to the review.

\section{Omissions and other criticisms}

1. The current PRF seems (to its author) weak in many ways. More people need to review the questions and the premises they are based upon. Some questions may be biased, or favor some personality types or approaches to work. We need input from a variety of sensitive and thoughtful people to make the PRF as useful as possible. The whole notion of characterization versus assessment in such a questionnaire needs to be examined better.

2. No detailed guidelines are developed for the employee Annual Progress Report.

3. The SEA as presented here might occupy a lot of paper. The PRF appears to require a couple of pages. Astute editing and layout might possibly reduce it to a single page, but that seems unlikely. Thus a typical SEA as a whole could well use 15-30 sheets of paper. This would have a negative impact on departmental requirements for copying, handling and filing. Some other organizations are utilizing scanning technology for storage of such documents, and that could be useful for archival storage of employee reviews.

As an overall business process, the SEA may well use less paper than our current system, because it emphasizes the use of original input. A web-based PRF might offer advantages in addition to reducing paper use, such as a tabular summary of all reviewer responses.

4. There is not an obvious home in the SEA for a job description. Many employees would choose to include it in their APR, but that is an optional component. Employees do have separate job descriptions on file; it might be reasonable to expand those slightly for use within a performance review, and add it to the supervisor summary if needed.

5. Use of the seven CAO performance criteria and the 6-point Engineering assessment scale may not be optimal for design of the PRF. Their use here is a compromise, to present a new system that in one sense changes as little as possible. Starting with a "clean sheet of paper" might yield a different and better assessment form.

\section{Confidentiality and the SEA}

The value of anonymous review comments may be dubious, but the issue has been raised in the past, and may well be a point of discussion in the context of this proposal. The structure of the PRF seems to allow the possibility of accepting confidential review comments, while also preserving their integrity. One possible protocol is sketched out in the following. Although a paper process is described, it may be adaptable to a web-based system.

The protocol is similar to that used for voting by mail. We would need a trusted third party, a proxy, to serve as a distribution and collection center for "ballots" (completed PRF's.) Administrators within our divisional or departmental office likely would be tasked with this duty. The PRF forms would need to be printed each with a unique identifying number.

When a complete list of reviewers for a given employee is received at the proxy office, an equal number of blank PRF forms, and a return envelope, are sealed into identical envelopes. This set of envelopes is shuffled, then addressed and mailed, each to one prospective reviewer. A database for the given employee notes the names of the reviewers, and the identifying numbers of the set of PRF forms mailed to them. However, due to the shuffle before addressing, no association is known between any particular name and number.

At the reviewer's end, he or she is instructed to complete the PRF, seal it in the return envelope provided, and sign the outside of the return envelope. As the returned ballots are received at the proxy office, a notation is made in the employee database that a given reviewer has returned the ballot, based on the external signature. However, the envelopes are not opened at this time.

When all reviews for a given employee have been returned, or when the review deadline passes, the envelopes for each employee are opened. The enclosed ballot is immediately separated from its enclosing envelope before inspection, and the envelopes are destroyed. The number on each ballot is then matched against the ones recorded in the database for that employee. This step verifies that the forms received are in fact the same as the ones sent out, and prevents any 
"smear campaign" utilizing anonymous (but bogus) ballots. There is still no association made, or required, between particular reviewers and their ballot, however. So long as the protocol for separating envelopes from ballots is followed, the only party that can positively claim any particular ballot is the person who completed it.

The protocol described here is not without weaknesses. There are many other methods and techniques to provide both confidentiality and integrity. There are other questions about the issue of confidentiality. This proposal has gone to some length to stress employee control over their own review process. Should an employee be forced to accept anonymous reviews of their performance? And if not, wouldn't the ones "most likely to need it" also be the ones likely to refuse? Hopefully, the presentation may stimulate further discussion in this area. 


\section{Personnel review for: \\ Reviewer's name (optional): \\ Date:}

\section{Instructions}

Please write the name of the person you are reviewing, your name, and today's date in the spaces provided above.

You are requested to help characterize and assess this employee's job performance by completing this questionnaire. There are seven job performance factors given below. The numbered questions or statements that follow each offer two contrasting ways of discussing that factor, labeled $\mathbf{A}$ or $\mathbf{B}$. There is generally no single "right" answer to these questions. As A or B seems to you a more accurate description of the person you are reviewing, place a mark closer to the $\mathbf{A}$ or $\mathbf{B}$ end of the scale provided. If they seem about equal, place your mark half-way between.

Please feel free to add additional commentary in the spaces provided, or to ignore any questions that don't seem pertinent to you.

An overall assessment question is at the end of each section. Score these questions by choosing the term you think best from the following six-point scale:

1. Routinely exceeds requirements

2. Often goes beyond what is required

3. Meets all requirements

4. Improvement recommended to meet requirements

5. Improvement required to meet requirements

6. Unsatisfactory

\section{Organizational Value}

1. This person brings value to the organization more by:

A. Working steadily behind the scenes; or

$\mathbf{A} \square \square \square \square \square \mathbf{B}$

2.

B. Taking visible positions, even if controversial.

A. Making ongoing contributions in an established area; or

$\mathbf{A} \square \square \square \square \square \mathbf{B}$

3.

B. Starting new projects.

A. Specializing in an area of particular skill; or

$\mathbf{A} \square \square \square \square \square \mathbf{B}$

4.

B. General problem solving in a wide area.

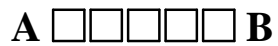

A. Being devoted to "pure" science/research; or

B. Focusing on institutional or programmatic goals.

Assessment of overall Organizational value:

$[1][2][3][4][5][6]$

Additional comments:

\section{Technical Ability and Professional Growth}

1. You would describe this individual's technical ability more as:

A. Analytical, logical, systematic, rational; or

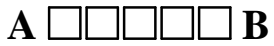

B. Intuitive - Has insights not supported by obvious facts and data.

2. In terms of technical ability, you would say this person primarily

A. Acts as a resource for others, teaches; or

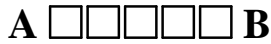

B. Focuses on learning new skills themself. 
3. In your opinion, this person's technical skills might be described more as

A. Specialized for their current assignment,

$\mathbf{A} \square \square \square \square \square \mathbf{B}$ often through long experience; or

B. Less differentiated by experience, adaptable, a generalist.

Assessment of Technical Ability and Professional Growth:

$[1][2][3][4][5][6]$

Additional comments:

\section{Quality}

1. This person's approach to achieving high quality in their work might be summarized as:

A. Finds a "good enough" solution, then moves on; or

$\mathbf{A} \square \square \square \square \square \mathbf{B}$

B. Strives for perfection in every detail.

2. When you think of this person and quality, do you think primarily of:

A. Quality as exemplified by their previous accomplishments; or

$\mathbf{A} \square \square \square \square \square$ B

B. Quality as a constant factor in their daily work?

3. Does this individual more:

A. Focus on quality as a mark of personal craftsmanship; or

$\mathbf{A} \square \square \square \square \square \mathbf{B}$

B. Inspire others to construct and incorporate quality in a systematic way?

4. Do you think this person mostly treats quality as:

A. An individual skill; or

$\mathbf{A} \square \square \square \square \square \mathbf{B}$

B. An institutional or team process?

Assessment of overall Quality:

$[1][2][3][4][5][6]$

Additional comments:

\section{Productivity}

1. When you consider this person's productivity, do you primarily:

A. See their productivity as a steady, day by day contribution; or

$\mathbf{A} \square \square \square \square \square \mathbf{B}$

B. A series of "brilliant flashes"?

2. This person's productivity can be characterized better as:

A. An individual contribution (energy); or

$\mathbf{A} \square \square \square \square \square \mathbf{B}$

B. Combines pieces of solutions from others (synergy).

3. Does this person tend to apply their productivity more by:

A. Solving a series of problems as posed; or

$\mathbf{A} \square \square \square \square \square \mathbf{B}$

B. Transforming the problem, "changing the rules"?

Assessment of overall Productivity:

$[1][2][3][4][5][6]$

Additional comments: 


\section{Communication and interpersonal skills}

1. In your opinion, this person's assignment requires:

A. Daily exercise of a broad range of communications skills; or

$\mathbf{A} \square \square \square \square \square \mathbf{B}$

B. More limited, focused communications.

2. In carrying out their job, this individual communicates:

A. With a broad spectrum of other workers; or

$\mathbf{A} \square \square \square \square \square \mathbf{B}$

B. Mostly within their immediate group.

3. You think of this person more as a:

A. Salesman, presenter, brainstormer; or

$\mathbf{A} \square \square \square \square \square \mathbf{B}$

B. Documentor, editor, author.

4. You would term this person's expressive style as more:

A. Direct, outspoken, candid; or

$\mathbf{A} \square \square \square \square \square$ B

B. Discreet, tactful, diplomatic.

5. This person could improve their (verbal) interactions with others by

A. Talking more; or

$\mathbf{A} \square \square \square \square \square \mathbf{B}$

B. Listening more.

Assessment of Communication and interpersonal skills:

$[1][2][3][4][5][6]$

Additional comments:

\section{Leadership and initiative}

1. In the area of leadership and initiative, does this person distinguish themself mostly:

A. By their individual contributions; or

$\mathbf{A} \square \square \square \square \square \mathbf{B}$

B. By facilitating team efforts?

2. Does this individual lead more by:

A. Fiat, e.g., issuing directives to others is an

$\mathbf{A} \square \square \square \square \square \mathbf{B}$ expected part of their assignment; or

B. Example, others follow their footsteps because of their accomplishments?

3. Does this person influence others more:

A. Within the organization; or

$\mathbf{A} \square \square \square \square \square \mathbf{B}$

B. External to their immediate group?

4. Would you characterize their leadership qualities more as:

A. Entrepreneurial, constantly breaking new ground; or

$\mathbf{A} \square \square \square \square \square \mathbf{B}$

B. Consistent leadership in an established set of areas?

5. Are their leadership qualities better expressed as:

A. Good brainstormer, develops novel approaches (good starter); or

$\mathbf{A} \square \square \square \square \square \mathbf{B}$

B. Strong followthrough, overcomes adversity (good finisher)?

6. As a decision-maker, would you say this person tends more:

A. To assess rapidly, make quick judgements; or

$\mathbf{A} \square \square \square \square \square \mathbf{B}$

B. Absorb all facets and facts, move slowly to judgement?

Assessment of Leadership:

$[1][2][3][4][5][6]$

Additional comments: 


\section{Complexity of assignment}

1. Does this person's assignment stress more:

A. Technical complexity, logical reasoning, science-based thinking; or

$\mathbf{A} \square \square \square \square \square \mathbf{B}$

B. Interpersonal complexity, political understanding, institutional knowledge?

2. Are the skills exhibited by this person as they perform their job more:

A. Skills based on experience, prior knowledge, formal education; or

$\mathbf{A} \square \square \square \square \square \mathbf{B}$

B. New skills, based on the short-term exigencies of the task?

3. Would you characterize the problems faced and solved by this person more as:

A. Well-bounded (though possibly of great difficulty); or

$\mathbf{A} \square \square \square \square \square \mathbf{B}$

B. Vaguely defined, open-ended?

Assessment of reviewee's response to Complexity:

$[1][2][3][4][5][6]$

Additional comments:

General comments:

Thank you for your time and consideration. Your responses will become a part of this reviewee's assessment. 
Employee Name:

Degree(s):

Classification:

Supervisor:

Years in Field:

Period Covered:

Prepared By:

Strike out un-needed text below:

Employee complies with established ES\&H regulations and procedures and performs duties in a manner that will not endanger the employee or other individuals or violate environmental regulations.

Employee maintains awareness of his ergonomic environment and takes periodic breaks, particularly during periods of extensive keyboard work.

Employee complies with established ES\&H regulations and procedures and understands the Laboratory's 5 Core Functions of ISM and that he is responsible for his own safety and the safety of those around him.

As a supervisor employee understands the management responsibility for safety and applies the seven principles to his actions.

While engaged in LLNL business, employee maintains behavior that accepts and values diversity that is consistent with the Laboratory's Equal Opportunity policy.

Employee signature/date

Supervisor signature/date 
SEA Certifications Form, v2.1 


\section{Please tell me what you thought of my proposal!}

\section{Overall SEA}

What did you think of the separate parts of the SEA?
A. Checklist style comments (PRF)?
B. Focus on characterization instead of assessment in PRF?
C. Employee option to do an APR?
D. Greater employee "ownership" of their APR?
E. Separate boilerplate document?
F. Option for confidential review comments?

Like $\square \square \square \square \square$ Dislike
Like $\square \square \square \square \square$ Dislike
Like $\square \square \square \square \square$ Dislike
Like $\square \square \square \square \square$ Dislike
Like $\square \square \square \square \square$ Dislike
Like $\square \square \square \square \square$ Dislike

Additional comments:

\section{Personnel Review Form (PRF)}

Were there questions in the PRF that you found especially irritating or useless? Alternately, were there any that you liked?

Is the proposal to use verbatim input from employees and others an important issue for you?

Do you think we should try to incorporate confidentiality of reviewer comments into our evaluation process?

Anything else you'd like to tell me?

\section{Thanks! Please fold and mail.}


To: Lee Busby

Mailstop: L-030 